\title{
Magnetic Solid-Phase Microextraction for Lead Detection in Aqueous Samples Using Magnetite Nanoparticles
}

\author{
Carolina A. S. Silva, ${ }^{a}$ Raphael L. S. e Silva, ${ }^{b}$ Alberthmeiry T. de Figueiredo ${ }^{a}$ and \\ Vanessa N. Alves ${ }^{\circledR} *, a$ \\ ${ }^{a}$ Unidade Acadêmica Especial de Química, Universidade Federal de Goiás, \\ 75704-020 Catalão-GO, Brazil \\ ${ }^{b}$ Instituto de Química, Universidade Federal de Goiás, 74690-900 Goiânia-GO, Brazil
}

\begin{abstract}
A magnetic solid-phase microextraction procedure was developed to detect lead in aqueous samples by flame atomic absorption spectrometry (FAAS). $\mathrm{Fe}_{3} \mathrm{O}_{4}$ nanoparticles were synthesized by coprecipitation and the crystalline phase was confirmed by X-ray diffraction. The point of zero charge (PZC) indicated that the oxide surface was negatively charged at $\mathrm{pH}$ levels above 9.4. $\mathrm{pH} 9.0$ is the best for adsorption and the influence of stirring time and adsorbent mass were analyzed and set at $4 \mathrm{~min}$ and $3.0 \mathrm{mg}$, respectively. The best desorption conditions were obtained for $500 \mu \mathrm{L}$ of $0.5 \mathrm{~mol} \mathrm{~L}^{-1} \mathrm{HNO}_{3}$ as eluant. The limit of quantification (LOQ) and relative standard deviation (RSD) were $16.48 \mu \mathrm{g} \mathrm{L}^{-1}$ and $0.25 \%$, respectively. The linear range was found to be $16.48-500 \mu \mathrm{g} \mathrm{L}^{-1}$. The accuracy was evaluated by recovery tests in mineral water, micellar water and aqueous makeup remover samples, showing values in the range of 95.94 to $118 \%$.
\end{abstract}

Keywords: magnetite, MSPE, lead

\section{Introduction}

Humans come into contact with a variety of metal ions in their daily lives, be it in air, water, industrialized products (cosmetics, toiletries, medicines, tattoo dyes, etc.) or in food (from fertilizers, packaging, pesticides, etc.), and this contact is often unavoidable. ${ }^{1}$ Lead is the type of metal ion that causes the greatest concern because it is highly toxic and widely used. Lead poisoning causes harmful effects to the central nervous system, blood, heart and kidneys. ${ }^{2}$

An important technique for trace lead determination in different types of samples, especially in aqueous samples, is flame atomic absorption spectrometry (FAAS), which is simpler and cheaper than other methods. ${ }^{3}$ Even with the high sensitivity of atomic spectroscopy techniques, a step of the analyte enrichment may be required depending on the type matrix. The use of solid-phase extraction (SPE) techniques has been frequently proposed for this purpose. ${ }^{4}$

Oliveira et al. ${ }^{5}$ developed an SPE method for the preconcentration of lead in chicken feed. The procedure involves $\mathrm{Pb}^{\mathrm{II}}$ adsorption in a column packed with Moringa oleifera husks. The limit of detection (LOD)

*e-mail: vanessanalves@gmail.com found was $1.66 \mu \mathrm{g} \mathrm{L}^{-1}$ and the precision, based on calculated repeatability, was below $1.3 \%$.

In addition to bioadsorbents, highly porous materials with high surface area have been used as adsorbents in SPE techniques. In this context, among the available adsorbents, nanostructured materials present good ability to adsorb toxic metallic ions and organic compounds in different types of samples. Thus, metallic oxides are widely applied in the adsorption of metallic ions in biological and environmental samples. ${ }^{6}$

Magnetic oxides such as magnetite $\left(\mathrm{Fe}_{3} \mathrm{O}_{4}\right)$ have received special attention in recent years because of their good adsorption capacity and promising potential for use in different fields of application. Thanks to their adsorptive potential and strong magnetic properties, these oxides are widely used to decontaminate water by removing metal ions, using a combination of adsorption and magnetic separation techniques. ${ }^{7,8}$

Magnetic solid-phase extraction (MSPE) is a technique that uses magnetic oxides as adsorbents. In this technique, magnetic particles (MPs) are added to the sample solution and the analyte is adsorbed onto the surface of the particles. The MPs are separated from the aqueous solution by an external magnetic force, and the analyte is easily desorbed 
by the eluant. ${ }^{9}$ As in classical SPE, the mechanisms by which the analyte is extracted involve interactions between analyte and functional groups or ions present on the MPs surface, such as hydrogen bonding, ionic, dipole-dipole, dipole-induced dipole and dispersion forces. ${ }^{10}$

Suleiman et al. ${ }^{11}$ developed a method to separate and preconcentrate $\mathrm{Cr}, \mathrm{Cu}$ and $\mathrm{Pb}$ traces in environmental samples by MSPE, using bismuthiol II immobilized magnetic nanoparticles. The method is characterized by its high enrichment factor, rapid separation and low LOD, and was successfully applied in river and lake water samples.

Behbahani et al. ${ }^{12}$ designed and utilized a nanogel composed of $\mathrm{Fe}_{3} \mathrm{O}_{4}$, silica and poly(4-vinylpyridine) as an adsorbent for the simultaneous separation of ultra-trace amounts of cadmium, lead, copper and nickel ions. Mehdinia et al..$^{13}$ developed a magnetic nanoadsorbent consisting of magnetite nanoparticles coated first with titanium dioxide and then with polypyrrole for MSPE of $\mathrm{Pb}^{\text {II }}$ trace.

Several studies found in the literature report the use of iron oxide nanoparticles in the development of analytical methodologies. However, most of the works used functionalized materials or that have undergone some previous treatment.

Thus, this study focused on the evaluation of the magnetite obtained by the coprecipitation method in the lead adsorption for the development of an MSPE methodology. The methodology developed will be applied in the lead determination in aqueous samples by FAAS. Since the magnetite nanoparticles used as adsorbent do not have any type of functionalization, the simplicity and low cost of synthesis are evidenced. Thus, the developed method obeys the current principles of green analytical chemistry.

\section{Experimental}

Instrumentation

Lead was detected using a Varian SpectrAA 220 FAAS (Mulgrave, Australia) equipped with a hollow cathode lamp and a deuterium lamp for background correction. The device was operated as recommended by the manufacturer. The $\mathrm{pH}$ of the samples and the working solutions was adjusted using a Gehaka PG1800 pHmeter (São Paulo, Brazil).

The solutions used in the extraction and elution steps were stirred in an XH-D vortex mixer (Global Trade Technology Co. Ltd., São Paulo, Brazil).

\section{Reagent solutions and samples}

The working solutions were prepared with water deionized in a Gehaka water purification system (São Paulo, Brazil). The reagents were of analytical grade. Before use, the laboratory glassware was left overnight in an aqueous solution of $10 \%(\mathrm{v} / \mathrm{v})$ nitric acid and then rinsed with deionized water.

Working solutions of lead were prepared daily by diluting a $1000 \mathrm{mg} \mathrm{L}^{-1}$ standard lead solution (Carlo Erba, Val de Reuil, France). The nitric acid solution used as eluant was prepared by diluting concentrated nitric acid obtained from Merck (Darmstadt, Germany) in water.

\section{Synthesis of magnetite nanoparticles}

Magnetite nanoparticles were obtained by the coprecipitation of $\mathrm{Fe}^{3+}\left(\mathrm{FeCl}_{3} \cdot 6 \mathrm{H}_{2} \mathrm{O}\right)$ and $\mathrm{Fe}^{2+}\left(\mathrm{FeSO}_{4} \cdot 7 \mathrm{H}_{2} \mathrm{O}\right)$ (Synth, São Paulo, Brazil) salts (molar ratio of 2:1), using an adapted version of a procedure described by Silva et $a l .{ }^{14}$ The overall reaction can be written as equation 1 :

$\mathrm{Fe}^{3+}+2 \mathrm{Fe}^{2+}+8 \mathrm{OH}^{-} \rightarrow \mathrm{Fe}_{3} \mathrm{O}_{4}+4 \mathrm{H}_{2} \mathrm{O}$

Lastly, the material obtained was oven-dried at $60{ }^{\circ} \mathrm{C}$ for $24 \mathrm{~h}^{.14}$

\section{Characterization of magnetite particles}

The crystal structure and crystallinity of the magnetite were analyzed by X-ray diffraction (XRD) $(\mathrm{CuK} \alpha$ radiation) in the $\theta-2 \theta$ scan mode ( $\theta$ is the diffraction angle), using a Shimadzu XRD 6100 diffractometer (Kyoto, Japan). The data were collected in fixed-time mode, from 20 to $80^{\circ}$ in the $2 \theta$ range, using a divergence slit of $0.5^{\circ}$, a receiving slit of $0.3 \mathrm{~mm}$, and a step size of $0.02^{\circ}$. The surface chemical bonds of the magnetite before and after the extraction process were detected by Fourier transform infrared spectroscopy (FTIR; Shimadzu IRPrestige-21, Tokyo, Japan). The powder samples were mixed with $\mathrm{KBr}$ in a $1: 100(\mathrm{~m} / \mathrm{v})$ ratio to produce tablets. The spectral range varied from 4000 to $400 \mathrm{~cm}^{-1}$, with 28 scans and $4 \mathrm{~cm}^{-1}$ resolution.

\section{Magnetic solid-phase microextraction method}

Aliquots of $5.0 \mathrm{~mL}$ of sample containing $1 \mathrm{mg} \mathrm{L}^{-1} \mathrm{~Pb}^{\mathrm{II}}$ under controlled $\mathrm{pH}$ (9.0) were poured into polyethylene flasks. Then, $3.0 \mathrm{mg}$ of magnetite nanoparticles were added to the flasks and stirred in a vortex mixer for $4.0 \mathrm{~min}$. The $\mathrm{Pb}^{\mathrm{II}}$ ions were adsorbed on the adsorbent surface and the 
magnetic nanoparticles containing adsorbed ions were separated with a magnet. The supernatant was discarded. The $\mathrm{Pb}^{\mathrm{II}}$ ions adsorbed on magnetic nanoparticles were eluted using $0.5 \mathrm{~mol} \mathrm{~L}^{-1} \mathrm{HNO}_{3}$ by stirring in a vortex mixer for $2 \mathrm{~min}$. After the elution step, the nanoparticles were collected using a magnet and the supernatant was analyzed by FAAS.

\section{Optimization of the extraction and elution steps}

The effect of $\mathrm{pH}$ on the adsorption of $\mathrm{Pb}^{\mathrm{II}}$ by magnetite nanoparticles was investigated at $\mathrm{pH}$ levels of $1,3,5$, 7, 9 and 12. The lead solution used in the optimization experiments was prepared in the concentration of $1 \mathrm{mg} \mathrm{L}^{-1}$.

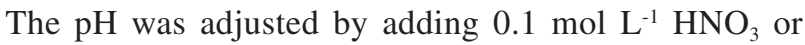
$\mathrm{NH}_{4} \mathrm{OH}$. In this experiment, the variables of adsorbent mass and stirring time were fixed at $6.3 \mathrm{mg}$ and $30 \mathrm{~min}$, respectively. After this time, the magnetite nanoparticles containing adsorbed $\mathrm{Pb}^{\Pi I}$ were collected with a magnet and the supernatant was analyzed by FAAS.

After selecting the best $\mathrm{pH}$ level for $\mathrm{Pb}^{\mathrm{II}}$ adsorption, the extraction variables were optimized using a univariate approach. The selected parameters were adsorbent mass and stirring time. In this experiment, the magnetite nanoparticles containing adsorbed $\mathrm{Pb}^{\mathrm{II}}$ were collected with a magnet and the supernatant was analyzed by FAAS.

To evaluate the influence of the magnetite mass on the extraction process, mass aliquots of 3.0, 6.0, 12.0, 25.0 and $50.0 \mathrm{mg}$ were investigated. These aliquots were stirred for 30 min with solutions of $\mathrm{Pb}^{\mathrm{II}}\left(1 \mathrm{mg} \mathrm{L}^{-1}\right)$ and $\mathrm{pH}$ 9.0. Then, the stirring time was studied in the range of 1 to $10 \mathrm{~min}$.

After optimizing the adsorption process, the desorption parameters were evaluated: eluant $\left(\mathrm{HNO}_{3}\right)$ concentrations of $0.1,0.5,1.0$ and $2.0 \mathrm{~mol} \mathrm{~L}^{-1}$ and elution times of 2, 4, 8, 10 and $12 \mathrm{~min}$. For this evaluation, the magnetite containing adsorbed $\mathrm{Pb}^{\mathrm{II}}$ was put into contact with the eluant at the above-cited concentrations. The magnetite was separated magnetically, and the eluate analyzed by FAAS.

\section{Study of interfering ions}

The effect of $\mathrm{Fe}^{\mathrm{II}}, \mathrm{Cu}^{\mathrm{II}}, \mathrm{K}^{\mathrm{I}}, \mathrm{Zn}^{\mathrm{II}}, \mathrm{Ca}^{\mathrm{II}}, \mathrm{Na}^{\mathrm{I}}, \mathrm{Mg}^{\mathrm{II}}, \mathrm{Co}^{\mathrm{II}}$, $\mathrm{Cd}^{\mathrm{II}}$ and $\mathrm{Cr}^{\mathrm{III}}$ was evaluated to determine the potential of these ions to interfere in the adsorption of $1.0 \mathrm{mg} \mathrm{L}^{-1}$ of lead solution by the preconcentration method.

The influence of potentially interfering ions was determined by comparing the analytical signals of a solution containing only $\mathrm{Pb}^{\Pi I}$ and a solution containing $\mathrm{Pb}^{\mathrm{II}}$ ions together with the potentially interfering ions. These solutions were preconcentrated and the interference factor ( IF = A' / A) was calculated. A' is the analytical signal for the solution containing the analyte in the presence of possible interferents, and $\mathrm{A}$ is the analytical signal for the solution containing $\mathrm{Pb}^{\mathrm{II}}$ in the absence of possible interferents. Species A was considered an interferent whenever the difference between the analytical signal for the solution containing only $\mathrm{Pb}^{\amalg I}$ ions and the solution that also contained possible interfering ions was higher than $10 \% .^{5}$

\section{Results and Discussion}

\section{Characterization of magnetite nanoparticles}

Since the synthesized material is completely magnetic, after preparation, the magnetite was completely removed from solution by magnetic decanting.

The method of synthesis and the concentration of reagents determine the chemical and physical properties of the synthesized nanoparticles, affecting their degree of crystallinity. ${ }^{15}$ Figure 1 depicts the XRD pattern of magnetite synthesized by coprecipitation.

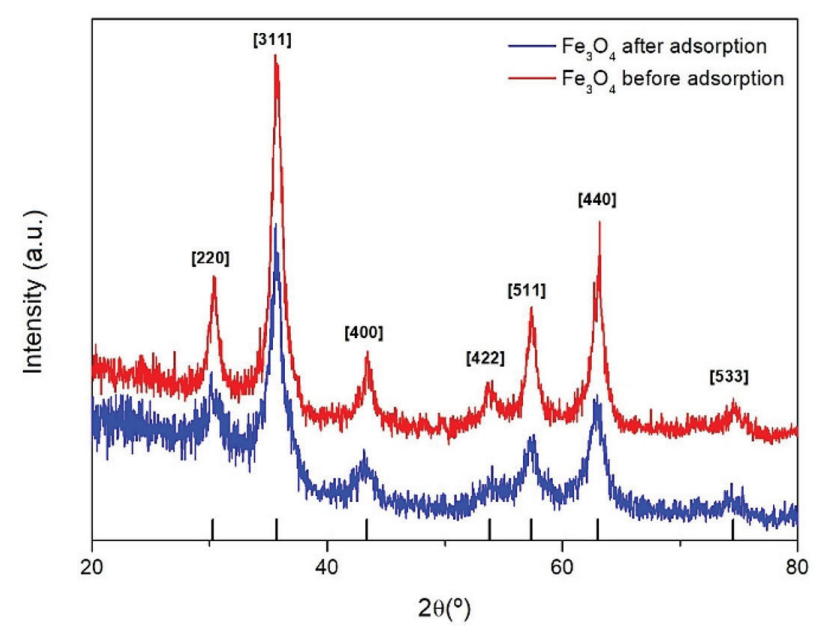

Figure 1. $\mathrm{Fe}_{3} \mathrm{O}_{4}$ diffratograms before and after adsorption.

Figure 1 depicts the profile of the magnetite nanoparticles used as adsorbent before and after the extraction of lead ions. After the $\mathrm{Fe}_{3} \mathrm{O}_{4}$ peaks were indexed, the cubic structure of magnetite was identified and found to be in good agreement with the Joint Committee on Powder Diffraction Standards (JCPDS) card No. 089-096. In addition, a comparison of the diffraction patterns and the crystallographic form of $\mathrm{Fe}_{3} \mathrm{O}_{4}$ revealed the absence of diffraction peaks for other phases, indicating that the synthesized material contained only the phase corresponding to the inverse spinel structure of the magnetite and that, after the lead was extracted, this structure did not undergo appreciable structural modifications. 
The mean crystallite size of the samples was calculated based on the peak width using the Debye-Scherrer equation, as: $D_{h k l}=\frac{0.89 \lambda}{\beta \cos \theta}$, where $D_{h k l}$ is the crystallite size, $\lambda$ is the $\mathrm{X}$-ray wavelength used (ca. $1.54056 \AA$ ), $\theta$ is the diffraction angle, and $\beta$ is the full width at half maximum (FWHM, in radians) of the diffraction peak (311). The calculated crystallite size was corrected using instrumental broadening and was found to be $7.95 \mathrm{~nm}$. Thus, the synthesized magnetite was nano-sized.

Adsorption is essentially a surface phenomenon, and any nano-sized materials have far larger surface areas than similar masses of larger scale materials. Thus, a larger amount of the magnetite can come into contact with the surrounding lead analyte, thereby increasing the adsorption.

Figure 2 shows the FTIR spectra of the magnetite before and after the adsorption process. Note the characteristic vibrations of the $\mathrm{Fe}-\mathrm{O}$ bonds of the magnetite at around 624 to $425 \mathrm{~cm}^{-1}$. The band at $1622 \mathrm{~cm}^{-1}$ is due to water molecules adsorbed on the magnetite surface. ${ }^{16,17}$ The characteristic $\mathrm{O}-\mathrm{H}$ bending vibrations are indicated by the bands at $3405 \mathrm{~cm}^{-1}$. After adsorption, there is a slight shift in the band centered at $567 \mathrm{~cm}^{-1}$, corresponding to the $\mathrm{Fe}-\mathrm{O}$ bonds, which shifts to $574 \mathrm{~cm}^{-1}$, indicating the formation of $\mathrm{Fe}-\mathrm{O}-\mathrm{Pb}$ on the magnetite surface. ${ }^{7,17}$

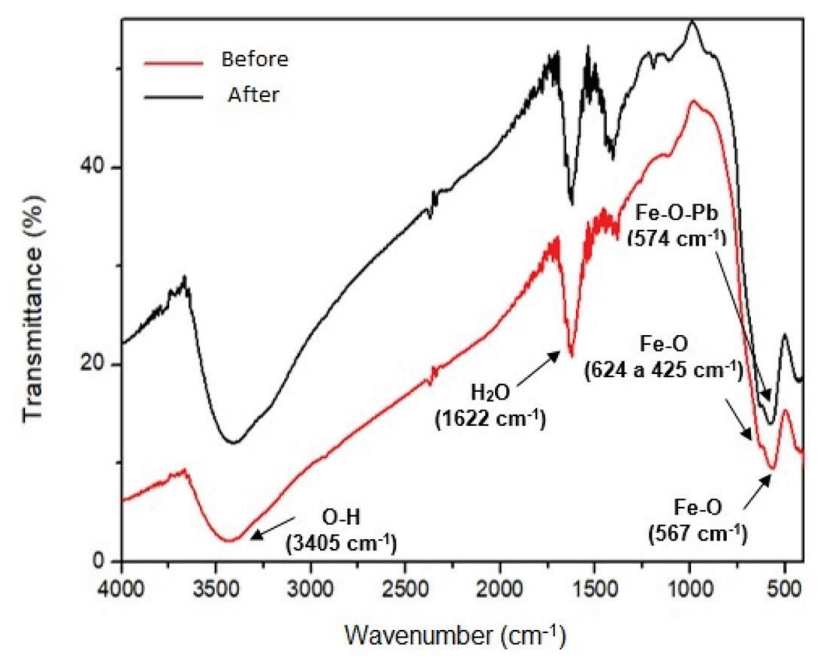

Figure 2. FTIR analysis of magnetite nanoparticles before and after adsorption.

\section{Optimization of the extraction and elution steps}

In the last few years, magnetite has been used in several scientific fields for a wide range of applications. Its adsorption potential has been evaluated against numerous organic and inorganic compounds. Thus, the influence of $\mathrm{pH}$ on $\mathrm{Pb}^{2+}$ adsorption by magnetite particles was evaluated, and this behavior is illustrated in Figure 3 .

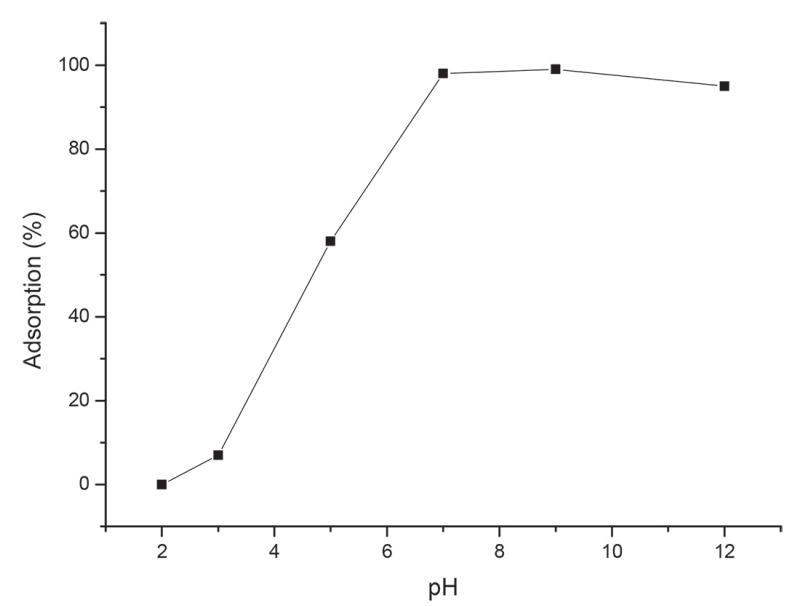

Figure 3. pH influence on lead adsorption.

High lead adsorption occurs between pH levels of 7.0 and 9.0. This behavior is probably due to the fact that, in aqueous media, the surface of magnetite is covered with $\mathrm{FeOH}$ groups. These groups can protonate or deprotonate to generate surface loads $\left(\mathrm{FeOH}_{2}{ }^{+}\right.$or $\left.\mathrm{FeO}^{-}\right)$, which vary according to $\mathrm{pH}$ levels below or above the $\mathrm{pH}_{\mathrm{PZC}}(\mathrm{pH}$ of the point of zero charge (PZC)), respectively. The $\mathrm{pH}_{\mathrm{PZC}}$ of this material is 9.4, indicating that below this value, the surface of the magnetite will contain groups with mostly positive loads $\left(\mathrm{FeOH}_{2}{ }^{+}\right)$, although the coexistence of a small number of groups with negative loads $\left(\mathrm{FeO}^{-}\right)$is possible. ${ }^{7}$ At $\mathrm{pH}$ levels between 7.0 and 9.0, lead has different species $\left(\mathrm{Pb}^{2+}\right.$, $\mathrm{Pb}(\mathrm{OH})^{+}$and $\left.\mathrm{Pb}(\mathrm{OH})_{2}\right)$. These species are electrostatically attracted by the surface loads of the coexisting magnetite species. This attraction causes a considerable increase in the adsorption of the lead species in these conditions.

The evaluation of the maximum adsorptive capacity of magnetite nanoparticles was evaluated by the construction of adsorption isotherms. The non-linear adjustment to the Langmuir, Freundlich and Sips models was evaluated.

The Sips model was the one that best represented the adsorption system; values for $\mathrm{X}^{2}$ (non-linear chi-square, 2.5847) and $\mathrm{R}^{2}$ (coefficient of determination, 0.9855), were observed for this model. The heterogeneity index $(\mathrm{nS}=0.4072)$ indicates that the system presents a mixed adsorption mechanism that at a given moment takes the form of Freundlich isotherm and subsequently takes the form of the Langmuir isotherm. ${ }^{18}$ The $\mathrm{Q}_{\max }$ value (maximum adsorption capacity, $31.68 \mathrm{mg} \mathrm{g}^{-1}$ ) indicates a good performance of the adsorbent.

In SPE procedures, the dose of adsorbent plays an important role in the adsorption of analytes. ${ }^{17}$ To determine the effects of adsorbent dose on the quantitative retention of lead, varying amounts of magnetite, ranging from 3.0 to $50.0 \mathrm{mg}$, were added to the lead solutions, and the MSPE method developed here was applied. Altering the amount 
of adsorbent mass does not cause significant changes in the adsorption efficiency of $\mathrm{Pb}^{\mathrm{II}}$ ions by magnetite. This means the process can be carried out using the smallest mass concentration evaluated in this study, i.e., $3.0 \mathrm{mg}$.

To ensure high adsorption efficiency and speed in the extraction process, the adsorption of $\mathrm{Pb}^{\mathrm{II}}$ by magnetite was evaluated within a range of 1 to $10 \mathrm{~min}$. It was found that the amount of ions $\mathrm{Pb}^{\mathrm{II}}$ adsorbed by magnetite in a time frame of 1 to 4 min increased considerably, thereafter remaining constant up to $10 \mathrm{~min}$. Therefore, to ensure the analytical frequency, a duration of 4 min was established as the optimal equilibrium time.

To determine the kinetic parameters of the adsorption mechanism of $\mathrm{Pb}^{\mathrm{II}}$ by magnetite, the experimental data was adjusted to the kinetic models of pseudo-first order, pseudosecond order and the Avrami fractional model, using the nonlinear method. Table 1 compares the parameters obtained for the three tested models.

Overall, the amounts of metal ion adsorbed per unit mass of the adsorbent at time $t\left(\mathrm{q}_{\mathrm{e}}\right)$ values calculated by the models and the $\mathrm{q}_{\mathrm{e}}$ values obtained experimentally showed no significant differences. However, the pseudo-first order model provided the best values of both $\mathrm{R}^{2}$ and $\mathrm{X}^{2}$, indicating that the adsorption rate in this process is proportional to the number of active sites available in the adsorbent material.

After determining the best conditions for $\mathrm{Pb}^{\mathrm{II}}$ adsorption, the desorption parameters were evaluated in order to identify the best conditions for the removal of $\mathrm{Pb}^{\mathrm{II}}$ adsorbed on the magnetite surface.

As shown in Figure 3, the adsorption process is highly dependent on the $\mathrm{pH}$, the adsorbed lead ions can be eluted from the magnetite surface with the decrease of the $\mathrm{pH}$ of the solution. Thus, nitric acid solutions were used as eluant.

The addition of acidic solutions alters the $\mathrm{pH}$ of the medium, leading to a change in the surface load of the adsorbent. Considering that the magnetite has a PZC of
9.4, its surface will be more positively charged and will repel lead ions present, favoring the desorption process.

The evaluation of desorption time and eluant concentrations used in the desorption process indicated that the best result was achieved with 2 min of desorption and $0.5 \mathrm{~mol} \mathrm{~L}^{-1}$ of nitric acid.

\section{Study of interfering ions}

It is well known that the efficiency of a preconcentration can be affected by the composition of the sample matrix. Therefore, the effect of some potentially interfering ions was evaluated. Our findings suggest that $\mathrm{Cd}^{\mathrm{II}}(\mathrm{IF}=0.86)$ and $\mathrm{Fe}^{\mathrm{III}}(\mathrm{IF}=0.67)$ ions favor a decrease in the analytical signal, indicating their negative interference in the process. However, the other ions $\left(\mathrm{Cu}^{\mathrm{II}}, \mathrm{K}^{\mathrm{I}}, \mathrm{Zn}^{\mathrm{II}}, \mathrm{Ca}^{\mathrm{II}}, \mathrm{Na}^{\mathrm{I}}, \mathrm{Mg}^{\mathrm{II}}\right.$, $\mathrm{Co}^{\mathrm{II}}$ and $\mathrm{Cr}^{\mathrm{III}}$ ) interfered positively, causing an increase in the analytical signal. This interference can usually be attributed to several factors, such as molecular mass, electronegativity and ionic radius. ${ }^{19}$ Another possibility is that this interference may occur not only in the solid phase of the adsorbent but also in the flame atomization step. ${ }^{20}$

\section{Analytical performance of the method}

Some analytical characteristics of the proposed method were evaluated after the system was optimized. The LOD was estimated to be three times the standard deviation of ten independent measurements of a blank sample divided by the slope of the calibration curve, and this value was $5.44 \mu \mathrm{g} \mathrm{L}^{-1}$. The linear range was 16.48 to $500 \mu \mathrm{g} \mathrm{L}^{-1}$, and the correlation coefficient was 0.999 . The repeatability of the proposed method was assessed by performing ten consecutive preconcentration steps at a concentration of $500 \mu \mathrm{g} \mathrm{L}{ }^{-1}$, whose results were expressed in terms of the relative standard deviation (RSD), which was equal to $0.25 \%$.

Table 1. Kinetic parameters for $\mathrm{Pb}^{\mathrm{II}}$ adsorption using $\mathrm{Fe}_{3} \mathrm{O}_{4}$ as adsorbent

\begin{tabular}{|c|c|c|c|c|c|}
\hline \multicolumn{6}{|c|}{ Pseudo-first order } \\
\hline $\mathrm{K}_{1} / \mathrm{min}^{-1}$ & $\mathrm{q}_{\mathrm{e}}$ calc. $/\left(\mathrm{mg} \mathrm{g}^{-1}\right)$ & $\mathrm{q}_{\mathrm{e}} \exp . /\left(\mathrm{mg} \mathrm{g}^{-1}\right)$ & $\mathrm{R}^{2}$ & $\mathrm{X}^{2}$ & \\
\hline 0.631 & 1.6888 & 1.6666 & 0.9299 & 0.0058 & \\
\hline \multicolumn{6}{|c|}{ Pseudo-second order } \\
\hline $\mathrm{K}_{2} / \min ^{-1}$ & $\mathrm{~h}_{\mathrm{o}} /\left(\mathrm{mg} \mathrm{g}^{-1} \mathrm{~min}^{-1}\right)$ & $\mathrm{q}_{\mathrm{e}}$ calc. $/\left(\mathrm{mg} \mathrm{g}^{-1}\right)$ & $\mathrm{q}_{\mathrm{e}} \exp . /\left(\mathrm{mg} \mathrm{g}^{-1}\right)$ & $\mathrm{R}^{2}$ & $\mathrm{X}^{2}$ \\
\hline 0.4252 & 1.61 & 1.9496 & 1.6666 & 0.9059 & 0.0078 \\
\hline \multicolumn{6}{|c|}{ Avrami } \\
\hline $\mathrm{K}_{\mathrm{AV}} / \min ^{-1}$ & $\mathrm{n}_{\mathrm{AV}}$ & $\mathrm{q}_{\mathrm{e}}$ calc. $/\left(\mathrm{mg} \mathrm{g}^{-1}\right)$ & $\mathrm{q}_{\mathrm{e}} \exp . /\left(\mathrm{mg} \mathrm{g}^{-1}\right)$ & $\mathrm{R}^{2}$ & $X^{2}$ \\
\hline 0.5362 & 0.8195 & 1.7029 & 1.6666 & 0.9247 & 0.0062 \\
\hline
\end{tabular}

$\mathrm{K}_{1}$ : pseudo-first order rate constant of the sorption process; $\mathrm{q}_{\mathrm{e}}$ calc. and $\mathrm{q}_{\mathrm{e}}$ exp.: calculated and experimental amounts of metal ion adsorbed per unit mass of the adsorbent at time $\mathrm{t}$, respectively; $\mathrm{R}^{2}$ : coefficient of determination; $\mathrm{X}^{2}$ : non-linear chi-square; $\mathrm{K}_{2}$ : pseudo-second order rate constant of the sorption process; $\mathrm{h}_{0}$ : initial adsorption rate; $\mathrm{K}_{\mathrm{AV}}$ : constant kinetics of Avrami; $\mathrm{n}_{\mathrm{AV}}$ : fractional order of the reaction related to the adsorption mechanism. 
In this work, the preconcentration factor was calculated according to other studies, ${ }^{5}$ as the ratio between the sensitivity of a calibration curve submitted to the preconcentration procedure and a calibration curve without the preconcentration. The sensitivity of the calibration curve submitted to the preconcentration was 0.0027 , while for the curve without preconcentration, the sensitivity obtained was $2 \times 10^{-5}$. Thus, the preconcentration factor obtained was 135 .

According to the Conselho Nacional do Meio Ambiente (CONAMA $)^{21}$ and the Environmental Protection Agency (EPA), ${ }^{22}$ the maximum allowable value for lead ions in effluents should not exceed $0.5 \mathrm{mg} \mathrm{L}^{-1}$, while for drinking water it is $0.05 \mathrm{mg} \mathrm{L}^{-1}$.

Compared to other extraction and preconcentration methods such as those developed by Baghban et al. ${ }^{23}$ and Carasek,$^{24}$ who presented LOD values of 100 and $10 \mu \mathrm{g} \mathrm{L}{ }^{-1}$, respectively, the proposed methodology is efficient.

The proposed method was applied to quantify lead in aqueous samples. $\mathrm{Pb}^{\mathrm{II}}$ was not detected in these samples, so the samples were spiked with $\mathrm{Pb}^{\mathrm{II}}$ to reach a final concentration of $25 \mu \mathrm{g} \mathrm{L}^{-1}$. As can be seen in Table 2, recovery rates of 95.54 to $118 \%$ were achieved.

Table 2. Relative recovery rates of the samples subjected to the proposed method

\begin{tabular}{lccc}
\hline \multirow{2}{*}{ Sample } & \multicolumn{2}{c}{$\mathrm{Pb}^{\mathrm{II}} /\left(\mu \mathrm{g} \mathrm{L}^{-1}\right)$} & \\
\cline { 2 - 3 } & Added & Found & Recovery / \% \\
\hline Micellar water 1 & 25.00 & 25.00 & 100.01 \\
Micellar water 2 & 25.00 & 25.01 & 100.05 \\
Micellar water 3 & 25.00 & 25.16 & 100.65 \\
Makeup remover & 25.00 & 24.07 & 96.29 \\
Mineral water 1 & 25.00 & 29.50 & 188.00 \\
Mineral water 2 & 25.00 & 27.27 & 109.09 \\
Mineral water 3 & 25.00 & 23.98 & 95.54 \\
\hline
\end{tabular}

The accuracy of the method was evaluated by analyzing a certified river water sample (APS-1071) with a certified lead concentration of $100.00 \pm 0.5 \mathrm{mg} \mathrm{L}^{-1}$. The reference material was subjected to MSPE, which resulted in $100.42 \pm 0.12 \mathrm{mg} \mathrm{L}^{-1}$. This is in good agreement with the certified values, confirming the reliability of the proposed method.

\section{Conclusions}

In this study, magnetic $\mathrm{Fe}_{3} \mathrm{O}_{4}$ nanopowder was prepared by a chemical coprecipitation method. The synthesized particles had a diameter of $7.95 \mathrm{~nm}$. The characterization results indicated that the material did not undergo structural changes in response to the adsorption of lead. Therefore, the MPs were used as a promising sorbent for the MSPE of trace amounts of lead in samples of mineral water, micellar water and makeup remover by FAAS. Magnetite provided excellent magnetic separation and dispersibility. The stability test, which consisted of successive cycles of separation / elution using $0.5 \mathrm{~mol} \mathrm{~L}^{-1} \mathrm{HNO}_{3}$ as eluant, indicated that the same batch of nanoparticles can be subjected to up to 10 cycles. The method provides good performance characteristics when compared to other FAAS methods described in the literature, and can be considered a simple and inexpensive method for the detection of lead in cosmetics and other aqueous media.

\section{Acknowledgments}

The present work was carried out with the support of the Coordenação de Aperfeiçoamento de Pessoal de Nível Superir (CAPES) - Brazil - Financing code 001. The authors gratefully acknowledge the Brazilian research funding agencies CNPq (Conselho Nacional de Desenvolvimento Científico e Tecnológico) and FAPEG (Fundação de Amparo à Pesquisa do Estado de Goiás) for their financial support of this work.

\section{References}

1. Marinovich, M.; Boraso, M. S.; Testai, E.; Galli, C. L.; Regul. Toxicol. Pharmacol. 2014, 69, 416.

2. Kleinubing, S. J.; Silva, M. G. C.; Cienc. Eng. 2006, 2, 83.

3. Yilmaz, E.; Soylak, M.; Talanta 2018, 15, 152.

4. Alves, V. N.; Neri, T. S.; Borges, S. S. O.; Carvalho, D. C.; Coelho, N. M. M.; Ecol. Eng. 2017, 106, 431.

5. Oliveira, J. A. N.; Siqueira, L. M. C.; de Sousa Neto, J. A.; Coelho, N. M. M.; Alves, V. N.; Microchem. J. 2017, 133, 4327.

6. Mortavazi, K.; Ghaed, M.; Roosta, M.; Montazerozohori, M. N.; Indian J. Sci. Technol. 2012, 5, 1983.

7. Rajput, S.; Pittman, C. U.; Mohan, D.; J. Colloid Interface Sci. 2016, 48, 334.

8. Shirani, M.; Habibollahi, S.; Akbari, A.; Food Chem. 2019, 30 , 304.

9. Arteaga, A. K.; Rodiguez, A. J.; Barrado, E.; Anal. Chim. Acta 2010, 64, 1657.

10. Zygler, A.; Wasik, A.; Namiésnik, J.; Talanta 2010, 82, 1742.

11. Suleiman, J. S.; Hu, B.; Peng, H.; Huang, C.; Talanta 2009, 77, 1579.

12. Behbahani, M.; Bide, Y.; Bagheri, S.; Salariam, M.; Omidi, F.; Nabid, M. R.; Microchim. Acta 2018, 183, 111.

13. Mehdinia, A.; Shoormeij, Z.; Jabbari, A.; Microchim. Acta 2017, 184, 1529. 
14. Silva, R. L. S.; Figueiredo, A. T.; Barrado, C. M.; Sousa, M. H.; Mater. Res. 2017, 20, 1317.

15. Lu, A.; Salabas, E. L.; Schuth, F.; Angew. Chem. 2007, 46, 122.

16. Kumari, M.; Pittman Jr., C. U.; Mohan, D.; J. Colloid Interface Sci. 2015, 442, 120.

17. Feist, B.; Food Chem. 2016, 209, 37.

18. Nagy, B.; Mânzatu, C.; Maicanranu, A.; Indolean, C.; Lucian, B.; Majdik, C.; Arabian J. Chem. 2017, 10, 569.

19. Nassar, N. N.; J. Hazard. Mater. 2010, 184, 538.

20. Tarley, C. R. T.; Ferreira, S. L. C.; Arruda, M. A. Z.; Microchem. J. 2004, 77, 163.
21. Conselho Nacional do Meio Ambiente (CONAMA); Resolução CONAMA No. 430 de 13/05/2011. Available at https://www. legisweb.com.br/legislacao/?id=114770, accessed in May 2019.

22. https://www.usa.gov/federal-agencies/environmentalprotection-agency, accessed in January 2019.

23. Baghban, N.; Yilmaz, E.; Soylak, M.; J. Mol. Liq. 2010, 34, 260.

24. Carasek, E.; Quim. Nova 2002, 25, 748.

Submitted: February 7, 2019

Published online: June 7, 2019 